\title{
Neuro-stimulation Techniques for the Management of Anxiety Disorders: An Update
}

\author{
Sujita Kumar Kar $^{1}$, Siddharth Sarkar ${ }^{2}$ \\ 'Department of Psychiatry, King George's Medical University, Lucknow, ${ }^{2}$ Department of Psychiatry and National Drug Dependence \\ Treatment Centre, All India Institute of Medical Sciences, New Delhi, India
}

\begin{abstract}
Neuro-stimulation techniques have gradually evolved over the decades and have emerged potential therapeutic modalities for the treatment of psychiatric disorders, especially treatment refractory cases. The neuro-stimulation techniques involves modalities like electroconvulsive therapy (ECT), repetitive transcranial magnetic stimulation (rTMS), transcranial direct current stimulation (tDCS), vagus nerve stimulation (VNS) and others. This review discusses the role of neuro-stimulation techniques in the treatment of anxiety disorders. The various modalities of neuro-stimulation techniques are briefly discussed. The evidence base relating to use of these techniques in the treatment of anxiety disorders is discussed further. The review then highlights the challenges in conducting research in relation to the use of neuro-stimulation techniques with reference to patients with anxiety disorders. The review provides the future directions of research and aimed at expanding the evidence base of treatment of anxiety disorders and providing neuro-stimulation techniques as promising effective and acceptable alternative in select cases.
\end{abstract}

KEY WORDS: Brain stimulation; Anxiety disorders; Therapeutic technique; Treatment refractory cases.

\section{INTRODUCTION}

Anxiety disorders are among the most common mental health problems worldwide. ${ }^{1,2)}$ These disorders are associated with considerable societal costs and impairment of quality of life. ${ }^{3,4)}$ Despite adequate pharmacotherapy and psychotherapy, many patients still remain symptomatic. Hence, there remains a need for other modalities as treatment options for anxiety disorder, especially in refractory cases.

Neuro-stimulation techniques provide a novel approach to treatment of patients with anxiety disorders. The neuro-stimulation techniques commonly refer to methods of stimulation of brain matter through electrical or magnetic impulses. The present review discusses the various neuro-stimulation techniques that have current or potential application for the treatment of patients with anxiety disorders.

\footnotetext{
Received: April 21, 2016 / Revised: May 30, 2016

Accepted: June 8, 2016

Address for correspondence: Sujita Kumar Kar, MD

Department of Psychiatry, King George's Medical University, Shah

Mina Road, Chowk, Lucknow 226003, Uttar Pradesh, India

Tel: +91-9956273747, Fax: +91-0522-2258642

E-mail: skkar1981@yahoo.com
}

\section{NEURO-STIMULAION METHODS}

Brain stimulation methods are an important modality of treatment developed over the last century for use in various neuro-psychiatric disorders. Table 1 summarizes various neuro-stimulation methods.

Electroconvulsive therapy (ECT) is the oldest neuro stimulation therapy developed in the early part of the nineteenth century $(1930 \mathrm{~s}){ }^{5,6)}$ The main goal of ECT is to produce a seizure through the electrical stimulation of the brain. Another modality of treatment with similar goal (to produce seizure for getting therapeutic effects) has been developed in 2000s in the form of magnetic seizure therapy (MST). ${ }^{6}$ In MST, seizure is induced for a therapeutic purpose through magnetic stimulation. ${ }^{7)}$ High frequency magnetic stimulation is given to produce seizure in MST and anesthetic agents and muscle relaxants are given to modify the visible seizure movements like ECT. Cognitive side effects are less and patients usually have short lasting seizures with MST in comparison to ECT, which makes it more acceptable. ${ }^{8)}$ Its efficacy is being studied in treatment resistant depression and the initial results are promising. ${ }^{9)}$ In MST, the magnetic stimulation is focal, producing focal seizures than generalized ones, hence it seems to be more safer than ECT; however, further studies

(a) This is an Open-Access article distributed under the terms of the Creative Commons Attribution Non-Commercial License (http://creativecommons.org/licenses/by-nc/4.0) which permits unrestricted non-commercial use, distribution, and reproduction in any medium, provided the original work is properly cited. 
Table 1. Neuro-stimulation techniques

\begin{tabular}{|c|c|c|c|}
\hline Neuro-stimulation technique & $\begin{array}{c}\text { Year of } \\
\text { development }\end{array}$ & Brief overview & Type of neuro-stimulation \\
\hline Electroconvulsive therapy (ECT) & 1930s & $\begin{array}{l}\text { Non-invasive, production of seizure through passage of } \\
\text { electrical current through the brain }\end{array}$ & Convulsive, diffuse \\
\hline Transcranial electrical stimulation & $1950 \mathrm{~s}$ & $\begin{array}{l}\text { Non-invasive, stimulation of brain by using electrical } \\
\text { stimulus without production of seizure, electrodes are } \\
\text { placed over the cranium }\end{array}$ & $\begin{array}{l}\text { Non-convulsive, diffuse to } \\
\text { focal }\end{array}$ \\
\hline $\begin{array}{l}\text { Transcranial direct current } \\
\text { stimulation (tDCS) }\end{array}$ & $1960 s$ & $\begin{array}{l}\text { Non-invasive, electrical stimulus passes between surface } \\
\text { electrodes (cathode and anode) producing either } \\
\text { neuronal depolarization or hyperpolarization }\end{array}$ & Non-convulsive, diffuse \\
\hline Vagus nerve stimulation (VNS) & 1980s & $\begin{array}{l}\text { Invasive, vagus nerve is stimulated to produce inhibition } \\
\text { of focal cortical areas }\end{array}$ & Non-convulsive, focal \\
\hline $\begin{array}{l}\text { Repetitive transcranial magnetic } \\
\text { stimulation (rTMS) }\end{array}$ & 1990s & $\begin{array}{l}\text { Non-invasive, magnetic stimulation to brain areas to either } \\
\text { stimulate or inhibit cortical neuronal function }\end{array}$ & Non-convulsive, focal \\
\hline Deep brain stimulation (DBS) & 1990s & $\begin{array}{l}\text { Invasive, electrodes implanted stereotactically and } \\
\text { stimulated through pulse generators }\end{array}$ & Non-convulsive, focal \\
\hline Epicranial stimulation (EpCS) & 2007 & $\begin{array}{l}\text { Minimally Invasive, electrode placed over a cranial nerve } \\
\text { or dura mater is stimulated using electrical pulse } \\
\text { generator }\end{array}$ & Non-convulsive, focal \\
\hline Magnetic seizure therapy (MTS) & 2008 & $\begin{array}{l}\text { Non-invasive, production of seizure through magnetic } \\
\text { stimulation. Produces a focal seizure }\end{array}$ & Convulsive, focal to diffuse \\
\hline
\end{tabular}

are needed to reach at this conclusion. ${ }^{7)}$

Transcranial electrical stimulation is a non-invasive method of neuro-stimulation, which was evolved over years and newer technologies has been incorporated to it, giving it different forms like transcranial pulsed current stimulation (tPCS), transcranial direct current stimulation (tDCS), cranial electrotherapy stimulation (CES), transcerebral electrotherapy (TCET), neuro-electric therapy (NET), transcutaneous cranial electrical stimulation (TCES), electroanesthesia (EA), transcranial alternating current stimulation (tACS), and transcranial random noise stimulation (tRNS). ${ }^{5)}$ Transcranial electrical stimulation includes all modalities of electro-stimulation used transcranially with electrodes and the electrical stimulus is often generated by batteries. ${ }^{10)}$

tDCS is a non-invasive method of neuro-stimulation, in which low strength electrical stimulus is applied on the skin surface of cranium. The electrical stimulus may traverse from the anode to cathode, which produces depolarization leading to cortical excitability, and its reverse cause hyperpolarization resulting in suppression of cortical excitability which results in therapeutic effect. ${ }^{11,12)}$ The depolarization and hyperpolarization response is being mediated through alteration in resting membrane potential of the neurons. ${ }^{13)}$

Epicranial stimulation (EpCS), is a minimally invasive technique of neuro-stimulation, where the electrode is placed over a cranial nerve (like occipital nerve) or over the dura mater and is electrically stimulated by the pulse generator. ${ }^{14)}$ It has been utilized in refractory headache. ${ }^{15)}$
Vagus nerve stimulation (VNS) is an important neuro-stimulation technique, where the vagus nerve is stimulated through electrical stimulus to produce inhibition of certain focal cortical activities, which in result helpful in various neuropsychiatric conditions like epilepsy, depression, anxiety disorder and dementia. ${ }^{16)}$ Vagus nerve is connected with important brain areas like locus ceruleus, amygdala, hippocampus, orbito-frontal cortex as well as insular cortex, which are involved in emotional and cognitive processing. ${ }^{17)}$

Repetitive transcranial magnetic stimulation (rTMS) is a non-invasive neurostimulation technique that is administered through a magnetic coil applied over the scalp. In the rTMS technique the magnetic field gets converted to electrical field on reaching the brain surface. ${ }^{18)}$ rTMS is found to be effective in various neuropsychiatric disorders like Parkinson's disease, Alzheimer's disease, dystonia, epilepsy, stroke, resistant depression, obsessive compulsive disorder (OCD), chronic pain, persistent auditory hallucination, autism, generalized anxiety disorder and posttraumatic stress disorder (PTSD). ${ }^{19)}$

In deep brain stimulation (DBS), electrode are implanted in specific brain areas, through stereotactic technique and stimulated through electrical pulse generators. ${ }^{20)}$ DBS is effective in psychiatric disorders like treatment resistant depression, treatment resistant obsessive compulsive disorder and Gilles de la Tourette syndrome. ${ }^{21)}$ However, in recent studies, DBS is also found to be effective in other psychiatric disorders like PTSD. ${ }^{22)}$ 
Table 2. Summary of evidence base

\begin{tabular}{ll}
\hline \multicolumn{1}{c}{ Neuro-stimulation method } & Level of evidence \\
\hline Electroconvulsive therapy (ECT) & OCD - CS; PTSD - OL \\
Transcranial electrical stimulation & OCD - OL; PTSD - OL; GAD - OL; phobia - OL; social anxiety disorder - OL \\
Transcranial direct current stimulation (tDCS) & OCD, PTSD, GAD - CR \\
Vagus nerve stimulation (VNS) & OCD, PTSD, Panic disorder - OL \\
Repetitive transcranial magnetic stimulation (rTMS) & OCD - SR, MA; PTSD - RCT; GAD - OL \\
Deep brain stimulation (DBS) & OCD - SR, DBRCT; PTSD - RCT; GAD - OL \\
\hline
\end{tabular}

OCD, obsessive compulsive disorder; CS, case series; PTSD, posttraumatic stress disorder; OL, open label trial; $G A D$, generalized anxiety disorder; CR, case report; SR, systematic review; MA, meta analysis; RCT, randomized controlled trial; DBRCT, double blind RCT.

\section{BRAIN STIMULATION TREATMENT OF ANXIETY DISORDER}

Various neuro-stimulation techniques have been utilized for the treatment of anxiety disorders. The evidence base for each of the techniques is highlighted in the following paragraphs and is summarized in Table 2.

\section{Electroconvulsive Therapy}

ECT is effective in improving the symptoms of OCD in pharmacotherapy and behavior therapy refractory cases as seen in several case studies. ${ }^{23,24)}$ There is no difference in unilateral or bilateral ECT, so far the treatment efficacy is concerned in OCD patients, as per the limited evidences available till now. ${ }^{11)}$ Though the standard guidelines do not approve ECT in the management of OCD, but it may be considered as an alternative option in treatment refractory cases and in presence of co-morbidities. ${ }^{25)}$

In a study on effectiveness of ECT in patients with co-morbid major depressive disorder and PTSD, Watts ${ }^{26)}$ found that ECT is effective in reducing the symptoms of depression as well as PTSD. In an open label study on 20 patients of treatment refractory PTSD, ECT was found to be effective in reducing the symptom severity by $40 \%{ }^{27)}$ Several case studies suggest that ECT is effective in ameliorating the symptoms of PTSD and OCD (late onset type, with co-morbidities like depression, Parkinson's disease, schizoaffective disorder). ${ }^{25,28-30)}$

The exact biological changes produced by ECT for the therapeutic response in anxiety disorders including OCD are not known. Modulation of the abnormal activity of the cortico-striato-thalamo-cortical loop may be responsible for clinical response to ECT in patients with OCD. ${ }^{11)}$

\section{Transcranial Electrical Stimulation}

Bystritsky et al. $^{31)}$ studied the effectiveness of transcranial electrical stimulation in patients of generalized anxiety disorder and found that electrical stimulus of 0.5 $\mathrm{Hz}$ frequency and 300-m $\mu \mathrm{A}$ intensity over six weeks peri- od to be effective in reducing the anxiety score significantly. Fontani et al., ${ }^{32)}$ in their study in patients with social anxiety disorder (SAD), found that non-invasive brain stimulation through radio electric asymmetric conveyor is effective in reducing the anxiety symptoms which is comparable with sertraline. Radio-electric stimulation of brain is also found to be effective in reducing the anxiety and depressive symptoms in patients with generalized anxiety disorder with co-morbid major depression. ${ }^{33)}$ Stimulation of brain using radio electric asymmetric conveyor was found to be effective in treatment of patients with pharmacotherapy resistant agoraphobia. ${ }^{34)}$

Transcranial electrical stimulation techniques remodulate the hyperfunctioning neuronal networks associated with fear and anxiety processing producing a normalizing response. $^{33)}$ This mechanism probably plays role in reducing the symptoms of anxiety.

\section{Transcranial Direct Current Stimulation}

The evidences regarding efficacy of tDCS in anxiety disorders is scarce. Conditions of cortical excitability like OCD and anxiety disorders can be targeted through cathodal stimulation, which is intended to reduce cortical excitability, but current evidences are not sufficient enough to prove this hypothesis. ${ }^{11)}$ The evidence of tDCS in generalized anxiety disorder is limited to single case report. ${ }^{35)}$

tDCS has been found to be effective in treatment resistant cases of OCD as reported in several case studies. ${ }^{36-38)}$ Cathodal stimulations are used in these cases in order to reduce cortical excitability. ${ }^{37,38)}$ Anodal stimulation at the pre supplementary motor area and supplementary motor area increases the inhibitory control; hence effective in controlling the symptoms of OCD. ${ }^{36}$

In OCD, the cortico-subcortical circuit (orbitofrontalstiato-thalamic) is in excited state, which gets modulated by tDCS producing the therapeutic response. ${ }^{11)}$ In a study on healthy volunteers, tDCS was applied to the dorso-lateral pre-frontal cortex (DLPFC; anodal stimulation of left DLPFC and cathodal stimulation of right DLPFC) and the 
vigilance to threatening stimuli was reported to be reduced. ${ }^{39)}$ It seems to have strong implication in management of anxiety disorders like PTSD, phobia and panic disorder as anxiety related to vigilance on threatening stimuli is observed in these conditions.

\section{Repetitive Transcranial Magnetic Stimulation}

Therapeutic response due to rTMS is mediated through modulation of the excitability of focal brain regions. ${ }^{11)}$ rTMS is capable of modulating the activity of superficial cortical zones. ${ }^{11)}$ In a Cochrane review, Martin et al. ${ }^{40)}$ concluded that the evidence is not conclusive regarding the efficacy of rTMS in treatment of OCD. Jaafari et al. ${ }^{41)}$ reviewed 12 open label and randomized, sham-controlled studies and found that rTMS targeting either supplementary motor cortex or orbito-frontal cortex is effective in controlling the symptoms of OCD; however, stimulation of DLPFC is ineffective. Neuro-navigational techniques are helpful in accurately localizing these brain areas and delivering the stimulus. ${ }^{41)}$ Berlim et al. ${ }^{42)}$ had conducted a meta-analysis of randomized controlled trials (RCTs) on rTMS in patients suffering from OCD and found active rTMS to be more efficacious than sham rTMS and that modulating the activity of orbito-frontal cortex and supplementary motor area of brain causes improvement in the OCD symptoms. ${ }^{42)}$ Modulation of the activity of the above areas helps in diminishing the excitability of cortico-striatial network, which is beneficial in patients with OCD. ${ }^{11)}$ High frequency and low frequency rTMS over DLPFC, modulates dopamine release and regional blood flow respectively on specific brain regions involved in OCD. ${ }^{11)}$

Watts et $a l .{ }^{43)}$ evaluated the efficacy of rTMS in patients with PTSD in comparison to sham rTMS and found that rTMS at a frequency of $1 \mathrm{~Hz}$, with 10 sessions delivered at the right DLPFC was effective in improving the symptoms of PTSD. rTMS applied to right sided DLPFC interferes with episodic memory in healthy individuals, which may be beneficial in patients with PTSD in whom the traumatic episodic memory retrieval can be potentially manipulated before it gets re-experienced. ${ }^{44)}$ Cohen et al., ${ }^{45)}$ in their double-blind, placebo-controlled trial, found that $10 \mathrm{~Hz}$ rTMS at $80 \%$ of motor threshold in 10 daily sessions over a period of two weeks to be effective in reducing the symptoms of PTSD and found it superior over low frequency rTMS. Findings of this study was replicated later in a larger double-blind, placebo-controlled study. ${ }^{46)}$ This study also revealed that high frequency rTMS (20 Hz rTMS used in this study) on right DLPFC improves the anxiety symptoms whereas stimulation of DLPFC in left side causes improvement in mood symptoms. ${ }^{46)}$

In a pilot study, Isserles et $a l^{47)}$ found that deep Transcranial magnetic stimulation targeting medial prefrontal cortex is also effective in patients with PTSD, who are resistant to conventional treatment. ${ }^{47)}$ In experimental animals as well as in human studies, inhibitory rTMS of prefrontal cortex has been found to be effective in patients with anxiety disorder like PTSD and panic disorder. ${ }^{48)}$

Though both low frequency and high frequency rTMS has been used in different studies for treatment of PTSD, but the existing evidences are favoring the role of high frequency rTMS in treatment. $^{49)}$

Bystritsky et al. ${ }^{50)}$ applied functional magnetic resonance imaging guided rTMS in patients of generalized anxiety disorder and found it an effective modality of treatment in this group of patients in their study. ${ }^{50)}$ Evidences are scarce regarding effectiveness of rTMS in adults with generalized anxiety disorder, though a systematic review highlights about the anxiolytic effects of rTMS. ${ }^{48,51)}$

Activity of amygdala, which mediates anxiety response, is controlled by the prefrontal cortex through its inhibitory inputs. Dysfunction of this cortical network occurs in various anxiety disorders like panic disorder and phobia as well as generalized anxiety disorder. The anxiolytic effect of rTMS is mediated by modulation of the hyperactive amygdala activity through the prefrontal cortex. $^{48)}$

Li et al. ${ }^{52)}$ had conducted a Cochrane database systematic review about role of rTMS in management of panic disorder. They found only two RCTs with small sample sizes using $1 \mathrm{~Hz}$ rTMS on right DLPFC, results of which are inconclusive. In another study with small sample of patients suffering from panic disorder with co-morbid depression, symptoms of both the disorders had improved with low frequency rTMS over right DLPFC. ${ }^{53)}$

The effectiveness of rTMS in social anxiety disorder was limited to case studies. ${ }^{54)}$ As medial prefrontal cortex is the most consistent zone of brain in anxiety processing, it was targeted in the therapy. ${ }^{54)}$ In this case study, it was found that low frequency rTMS and high frequency rTMS targeting the right and left medial prefrontal cortex respectively for four weeks was effective in the treatment of social anxiety disorder. ${ }^{54}$

\section{Deep Brain Stimulation}

Genesis of OCD is a severe mental health problem, which has been suggested to be related to over-activity of 
cortico-striato-thalamo-cortical loop. Here, the basal ganglia (striatum) has an important role, hence DBS, targeting this area helps in improving the psychopathology. ${ }^{55)}$ Similarly, Seijo-Zazo et al. ${ }^{56)}$ also suggested that DBS of limbic part of sub-thalamic nucleus may be helpful in refractory OCD. This again is a part of cortico-subcortical loop, and targeting the elements of the loop is likely to cause improvement in the symptoms of OCD. Islam et $a l .,{ }^{57)}$ in their study on DBS in treatment resistant OCD, had targeted two separate brain areas - nucleus accumbens and bed nucleus of stria terminalis in two halves of patient sample and found that DBS of both the brain areas are safe and effective. ${ }^{57)}$ DBS targeting nucleus accumbens causes release of dopamine in the striatum, through which it causes improvement of symptoms of OCD ${ }^{58)}$ Nucleus accumbens also has a modulatory role in flow of information between important brain structures like amygdala, corpus striatum, meso-limbic areas related to dopaminergic transmission, medio-dorsal thalamus and prefrontal cortex which are associated with OCD and other anxiety disorders. ${ }^{59)}$

In their study on patients with treatment resistant OCD, van den Munckhof et al., ${ }^{60)}$ found that DBS targeting stimulation of nucleus accumbens actually stimulate the surrounding areas more, which might be responsible for the therapeutic effect and hence proposed that the important surrounding structure - ventral part of anterior limb of internal capsule stimulation possibly contributes to the clinical response. ${ }^{60)}$ Different studies suggest that DBS of other brain areas like sub-thalamic nucleus, ventral striatum, and inferior thalamic peduncle may be beneficial in treatment resistant OCD. ${ }^{61-65)}$

Inferior thalamic peduncle is an important link with orbitofrontal cortex and it has also connection with the cortico-striato-thalamo-cortical loop, which is involved in OCD. ${ }^{11)}$ DBS targeting the inferior thamic peduncle improves the symptoms of $\mathrm{OCD}$ by modulating the activity of the associated areas. ${ }^{11)}$ Kohl et al. ${ }^{65)}$ in their systematic review, mentioned that DBS applied to inferior thalamic peduncle is more efficacious in comparison to DBS of other brain areas; however, a small sample size limits the relevance of this finding. In a study on experimental animals, using high frequency stimulation of nucleus accumbens revealed that possible suppression of cholinergic interneurons have a role in stabilizing the hyperactivity of the prefrontal cortex in OCD. ${ }^{66)}$

Stidd et al $^{677}$ had used DBS as a treatment modality focusing on amygdala to treat patients with PTSD and found that stimulation of amygdala controls its excessive firing, hence can be promising option in management of PTSD. In patients with PTSD, there is increase in the volume of the amygdala, while the volume of several other brain structures like subgenual anterior cingulated gyrus, caudate nucleus, hypothalamus, left middle temporal gyrus including the insular cortex, and right middle frontal gyrus are found to be reduced. ${ }^{68-70)}$ High frequency DBS targeting the baso-lateral amygdala has been found to reduce the hyperactivity of amygdala, causing improvement in the PTSD symptoms. ${ }^{68,71)}$ Langevin et al., ${ }^{71)}$ in their study on experimental animals, applied DBS to right baso-lateral amygdala which was found to be effective in control of fear symptoms of PTSD.

\section{Vagus Nerve Stimulation}

The areas of brain connected to vagus nerve which includes locus ceruleus, hippocampus, orbito-frontal cortex, amygdala and insular cortex are also responsible for processing the psycho-somatic elements of anxiety, making VNS to be a potential therapeutic modality in anxiety management. ${ }^{14,17)}$ George et al., ${ }^{17)}$ in their pilot study of VNS in anxiety disorders, studied the short-term as well as long-term efficacy of VNS in patients of treatment resistant OCD, panic disorder and PTSD and found favorable outcomes. The fear response in patients with PTSD is resistant to extinction and VNS has been found to facilitate the process of extinction of the conditioned fear response in animal model. ${ }^{72)}$

\section{Other Modalities like Epicranial Stimulation and Magnetic Seizure Therapy}

There is no evidence of use of EpCS or MST for treatment of anxiety disorders as per the current evidence. However, these neuro-stimulation modalities may be taken in future research in psychiatric disorders including anxiety disorders, where focal cortical stimulation is required.

\section{CHALLENGES IN RESEARCH}

Despite of availability of numerous neuro-stimulation techniques and their advancement over decades, their applicability and clinical utility are restricted to few psychiatric disorders. Several challenges to research of neuro-stimulaiton techniques for psychiatric disorders in general and anxiety disorders in specific have been encountered. These are discussed as follows.

The first relates to methodological design. It is quite difficult to devise sham procedures for evaluation of the neu- 
ro-stimulation techniques in a randomized controlled blinded design. Also, the consensus on locations of the stimulus to be delivered and the dose requirement requires refinement with reiteration, which may require large and diverse samples of patients. The effect of concurrent medications and/or psychotherapy also needs to be considered while attributing efficacy.

The second issue relates to the heterogeneity of psychiatric disorders. The phenomenology of anxiety disorders can have variable expression leading to differences in the areas of brain being involved. Also, the different symptoms of anxiety may occur together in varying combinations, thus requiring refinement in the quantum and pattern of neuro-stimulation delivered based upon the disorder. The third issue relates to feasibility of the conduct of the studies. Many neuro-stimulation techniques are invasive and require neurosurgical assistance. Moreover, the technicality associated with the implementation of these therapeutic modalities needs trained manpower and considerable material investment. Furthermore, getting consent from anxious patients for invasive procedures may be a daunting task.

Studies have been limited by small sample sizes till now as only refractory cases are taken up for these neuro-stimulation techniques. With time, however, more evidence may accrue from even single case reports, case series as well as larger trials about which patients may be most suitable for these techniques.

\section{CONCLUSION}

Neuro-stimulation techniques are evolving as alternate effective treatment modalities in management of anxiety disorders. As per the current evidences, most of the neuro-stimulation techniques have been suggested for patients with treatment resistant anxiety disorder and many of them are yet receive regulatory approvals treatment of anxiety disorders. Further systematic research may help to provide better answers to the indications, operational methodologies, clinical outcome, safety profile and client acceptability of these neuro-stimulation techniques.

\section{REFERENCES}

1. Kessler RC, Angermeyer M, Anthony JC, DE Graaf R, Demyttenaere K, Gasquet I, et al. Lifetime prevalence and age-of-onset distributions of mental disorders in the World Health Organization's World Mental Health Survey Initiative. World Psychiatry 2007;6:168-176.

2. Kessler RC, Ruscio AM, Shear K, Wittchen HU. Epidemiology of anxiety disorders. Curr Top Behav Neurosci 2010;2: 21-35.
3. Lépine JP. The epidemiology of anxiety disorders: prevalence and societal costs. J Clin Psychiatry 2002;63 Suppl 14:4-8.

4. Olatunji BO, Cisler JM, Tolin DF. Quality of life in the anxiety disorders: a meta-analytic review. Clin Psychol Rev 2007;27:572-581.

5. Guleyupoglu B, Schestatsky P, Edwards D, Fregni F, Bikson M. Classification of methods in transcranial electrical stimulation (tES) and evolving strategy from historical approaches to contemporary innovations. $J$ Neurosci Methods 2013;219:297-311.

6. Hoy KE, Fitzgerald PB. Brain stimulation in psychiatry and its effects on cognition. Nat Rev Neurol 2010;6:267-275.

7. Rowny SB, Benzl K, Lisanby SH. Translational development strategy for magnetic seizure therapy. Exp Neurol 2009;219:27-35.

8. Spellman T, McClintock SM, Terrace H, Luber B, Husain MM, Lisanby SH. Differential effects of high-dose magnetic seizure therapy and electroconvulsive shock on cognitive function. Biol Psychiatry 2008;63:1163-1170.

9. Lisanby SH, Luber B, Schlaepfer TE, Sackeim HA. Safety and feasibility of magnetic seizure therapy (MST) in major depression: randomized within-subject comparison with electroconvulsive therapy. Neuropsychopharmacology 2003; 28:1852-1865.

10. Fertonani A, Ferrari C, Miniussi C. What do you feel if I apply transcranial electric stimulation? Safety, sensations and secondary induced effects. Clin Neurophysiol 2015; 126:2181-2188.

11. Bais M, Figee M, Denys D. Neuromodulation in obsessivecompulsive disorder. Psychiatr Clin North Am 2014;37:393413.

12. Paulus W. Transcranial electrical stimulation (tES - tDCS; tRNS, tACS) methods. Neuropsychol Rehabil 2011;21:602617.

13. Min JA, Lee SY, Lee CU, Chae JH. Psychiatric application of transcranial direct current stimulation (tDCS). Clin Psychopharmacol Neurosci 2010;8:117-126.

14. Novakovic V, Sher L, Lapidus KA, Mindes J, A Golier J, Yehuda R. Brain stimulation in posttraumatic stress disorder. Eur J Psychotraumatol 2011;2:10.3402/ejpt.v2i0. 5609.

15. Deshpande KK, Wininger KL. Feasibility of combined epicranial temporal and occipital neurostimulation: treatment of a challenging case of headache. Pain Physician 2011;14:37-44.

16. Groves DA, Brown VJ. Vagal nerve stimulation: a review of its applications and potential mechanisms that mediate its clinical effects. Neurosci Biobehav Rev 2005;29:493-500.

17. George MS, Ward HE Jr, Ninan PT, Pollack M, Nahas Z, Anderson $\mathrm{B}$, et al. A pilot study of vagus nerve stimulation (VNS) for treatment-resistant anxiety disorders. Brain Stimul 2008; 1:112-121.

18. Millet B. Electrostimulation techniques in treatment for severe depression. Encephale 2009;35 Suppl 7:S325-S329.

19. Leon-Sarmiento FE, Granadillo E, Bayona EA. Present and future of the transcranial magnetic stimulation. Invest Clin 2013;54:74-89.

20. Mohr P, Rodriguez M, Slavíčková A, Hanka J. The application of vagus nerve stimulation and deep brain stimulation in depression. Neuropsychobiology 2011;64:170-181.

21. Overbeek JM, de Koning P, Luigjes J, van den Munckhof P, Schuurman PR, Denys D. Deep brain stimulation for psychiatric disorders. Ned Tijdschr Geneeskd 2013;157: A7015. 
22. Luigjes J, van den Brink W, Feenstra M, van den Munckhof $\mathrm{P}$, Schuurman PR, Schippers R, et al. Deep brain stimulation in addiction: a review of potential brain targets. Mol Psychiatry 2012;17:572-583.

23. Mellman LA, Gorman JM. Successful treatment of obsessive-compulsive disorder with ECT. Am J Psychiatry 1984;141:596-597.

24. Maletzky B, McFarland B, Burt A. Refractory obsessive compulsive disorder and ECT. Convuls Ther 1994;10:34-42.

25. Hanisch F, Friedemann J, Piro J, Gutmann P. Maintenance electroconvulsive therapy for comorbid pharmacotherapyrefractory obsessive-compulsive and schizoaffective disorder. Eur J Med Res 2009;14:367-368.

26. Watts BV. Electroconvulsive therapy for comorbid major depressive disorder and posttraumatic stress disorder. J ECT 2007;23:93-95.

27. Margoob MA, Ali Z, Andrade C. Efficacy of ECT in chronic, severe, antidepressant- and CBT-refractory PTSD: An open, prospective study. Brain Stimul 2010;3:28-35.

28. Gadit AM, Smigas T. Efficacy of ECT in severe obsessive-compulsive disorder with Parkinson's disease. BMJ Case Rep 2012;2012:bcr0120125675.

29. Andrade C, Mushtaq D, Margoob MA. Electroconvulsive therapy for posttraumatic stress disorder: the importance of assessment measures. J ECT 2011;27:341.

30. Loi S, Bonwick R. Electroconvulsive therapy for treatment of late-onset obsessive compulsive disorder. Int Psychogeriatr 2010;22:830-831.

31. Bystritsky A, Kerwin L, Feusner J. A pilot study of cranial electrotherapy stimulation for generalized anxiety disorder. $J$ Clin Psychiatry 2008;69:412-417.

32. Fontani V, Mannu P, Castagna A, Rinaldi S. Social anxiety disorder: radio electric asymmetric conveyor brain stimulation versus sertraline. Patient Prefer Adherence 2011;5: 581-586.

33. Olivieri EB, Vecchiato C, Ignaccolo N, Mannu P, Castagna A, Aravagli L, et al. Radioelectric brain stimulation in the treatment of generalized anxiety disorder with comorbid major depression in a psychiatric hospital: a pilot study. Neuropsychiatr Dis Treat 2011;7:449-455.

34. Mannu P, Rinaldi S, Fontani V, Castagna A, Margotti ML. Noninvasive brain stimulation by radioelectric asymmetric conveyor in the treatment of agoraphobia: open-label, naturalistic study. Patient Prefer Adherence 2011;5:575580.

35. Shiozawa P, Leiva AP, Castro CD, da Silva ME, Cordeiro $\mathrm{Q}$, Fregni $\mathrm{F}$, et al. Transcranial direct current stimulation for generalized anxiety disorder: a case study. Biol Psychiatry 2014; 75:e17-e18.

36. Narayanaswamy JC, Jose D, Chhabra H, Agarwal SM, Shrinivasa B, Hegde A, et al. Successful application of add-on Transcranial Direct Current Stimulation (tDCS) for treatment of SSRI resistant OCD. Brain Stimul 2015;8:655657.

37. Mondino M, Haesebaert F, Poulet E, Saoud M, Brunelin J. Efficacy of cathodal transcranial direct current stimulation over the left orbitofrontal cortex in a patient with treatmentresistant obsessive-compulsive disorder. J ECT 2015;31: 271-272.

38. D'Urso G, Brunoni AR, Anastasia A, Micillo M, de Bartolomeis A, Mantovani A. Polarity-dependent effects of transcranial direct current stimulation in obsessive-compulsive disorder. Neurocase 2016;22:60-64.

39. Ironside M, O'Shea J, Cowen PJ, Harmer CJ. Frontal cortex stimulation reduces vigilance to threat: implications for the treatment of depression and anxiety. Biol Psychiatry 2016; 79:823-830.

40. Martin JL, Barbanoj MJ, Pérez V, Sacristán M. Transcranial magnetic stimulation for the treatment of obsessive-compulsive disorder. Cochrane Database Syst Rev 2003;(3):CD003387.

41. Jaafari N, Rachid F, Rotge JY, Polosan M, El-Hage W, Belin $\mathrm{D}$, et al. Safety and efficacy of repetitive transcranial magnetic stimulation in the treatment of obsessive-compulsive disorder: a review. World J Biol Psychiatry 2012;13:164177.

42. Berlim MT, Neufeld NH, Van den Eynde F. Repetitive transcranial magnetic stimulation (rTMS) for obsessivecompulsive disorder (OCD): an exploratory meta-analysis of randomized and sham-controlled trials. J Psychiatr Res 2013;47:999-1006.

43. Watts BV, Landon B, Groft A, Young-Xu Y. A sham controlled study of repetitive transcranial magnetic stimulation for posttraumatic stress disorder. Brain Stimul 2012; 5:38-43.

44. Rossi S, Cappa SF, Ulivelli M, De Capua A, Bartalini S, Rossini PM. rTMS for PTSD: induced merciful oblivion or elimination of abnormal hypermnesia? Behav Neurol 2006; 17:195-199.

45. Cohen H, Kaplan Z, Kotler M, Kouperman I, Moisa R, Grisaru N. Repetitive transcranial magnetic stimulation of the right dorsolateral prefrontal cortex in posttraumatic stress disorder: a double-blind, placebo-controlled study. Am J Psychiatry 2004;161:515-524.

46. Boggio PS, Rocha M, Oliveira MO, Fecteau S, Cohen RB, Campanhã $\mathrm{C}$, et al. Noninvasive brain stimulation with high-frequency and low-intensity repetitive transcranial magnetic stimulation treatment for posttraumatic stress disorder. J Clin Psychiatry 2010;71:992-999.

47. Isserles M, Shalev AY, Roth Y, Peri T, Kutz I, Zlotnick E, et al. Effectiveness of deep transcranial magnetic stimulation combined with a brief exposure procedure in post-traumatic stress disorder--a pilot study. Brain Stimul 2013;6:377-383.

48. Zwanzger P, Fallgatter AJ, Zavorotnyy M, Padberg F. Anxiolytic effects of transcranial magnetic stimulation--an alternative treatment option in anxiety disorders? J Neural Transm (Vienna) 2009;116:767-775.

49. Lefaucheur JP, André-Obadia N, Antal A, Ayache SS, Baeken C, Benninger DH, et al. Evidence-based guidelines on the therapeutic use of repetitive transcranial magnetic stimulation (rTMS). Clin Neurophysiol 2014;125:2150-2206.

50. Bystritsky A, Kaplan JT, Feusner JD, Kerwin LE, Wadekar M, Burock M, et al. A preliminary study of fMRI-guided rTMS in the treatment of generalized anxiety disorder. $J$ Clin Psychiatry 2008;69:1092-1098.

51. Transcranial Magnetic Stimulation for the treatment of adults with PTSD, GAD, or depression: A review of clinical effectiveness and guidelines [Internet]. Ottawa (ON): Canadian Agency for Drugs and Technologies in Health; 2014 Oct 31 [cited at 2016 Nov 1]. Available from http://www.ncbi.nlm.nih.gov/books/NBK254055/.

52. $\mathrm{Li} \mathrm{H}$, Wang J, Li C, Xiao Z. Repetitive Transcranial Magnetic Stimulation (rTMS) for panic disorder in adults. Cochrane Database Syst Rev 2014;(9):CD009083.

53. Mantovani A, Lisanby SH, Pieraccini F, Ulivelli M, Castrogiovanni P, Rossi S. Repetitive Transcranial Magnetic Stimulation (rTMS) in the treatment of panic disorder (PD) with comorbid major depression. J Affect Disord 2007;102: 277-280.

54. Paes F, Baczynski T, Novaes F, Marinho T, Arias-Carrión $\mathrm{O}$, Budde $\mathrm{H}$, et al. Repetitive transcranial magnetic 
stimulation (rTMS) to treat social anxiety disorder: case reports and a review of the literature. Clin Pract Epidemiol Ment Health 2013;9:180-188.

55. Haynes WI, Millet B, Mallet L. Obsessive-compulsive disorder, a new model of basal ganglia dysfunction? Elements from deep brain stimulation studies. Rev Neurol (Paris) 2012;168:649-654.

56. Seijo-Zazo E, Seijo-Fernández F, Fernández-González F, Alvarez-Vega MA, Lozano-Aragoneses B. A proposed new target for deep brain stimulation in obsessive-compulsive disorder. Rev Neurol 2007;45:424-428.

57. Islam L, Franzini A, Messina G, Scarone S, Gambini O. Deep brain stimulation of the nucleus accumbens and bed nucleus of stria terminalis for obsessive-compulsive disorder: a case series. World Neurosurg 2015;83:657-663.

58. Figee M, de Koning P, Klaassen S, Vulink N, Mantione M, van den Munckhof $\mathrm{P}$, et al. Deep brain stimulation induces striatal dopamine release in obsessive-compulsive disorder. Biol Psychiatry 2014;75:647-652.

59. Sturm V, Lenartz D, Koulousakis A, Treuer H, Herholz K, Klein JC, et al. The nucleus accumbens: a target for deep brain stimulation in obsessive-compulsive- and anxietydisorders. J Chem Neuroanat 2003;26:293-299.

60. van den Munckhof P, Bosch DA, Mantione MH, Figee M, Denys DA, Schuurman PR. Active stimulation site of nucleus accumbens deep brain stimulation in obsessivecompulsive disorder is localized in the ventral internal capsule. Acta Neurochir Suppl 2013;117:53-59.

61. de Koning PP, Figee M, van den Munckhof P, Schuurman PR, Denys D. Current status of deep brain stimulation for obsessive-compulsive disorder: a clinical review of different targets. Curr Psychiatry Rep 2011;13:274-282.

62. Williams NR, Okun MS. Deep brain stimulation (DBS) at the interface of neurology and psychiatry. $J$ Clin Invest 2013;123:4546-4556.

63. Chabardès S, Polosan M, Krack P, Bastin J, Krainik A, David $\mathrm{O}$, et al. Deep brain stimulation for obsessivecompulsive disorder: subthalamic nucleus target. World Neurosurg 2013;80:S31.e1-e8.

64. Greenberg BD, Malone DA, Friehs GM, Rezai AR, Kubu
CS, Malloy PF, et al. Three-year outcomes in deep brain stimulation for highly resistant obsessive-compulsive disorder. Neuropsychopharmacology 2006;31:2384-2393.

65. Kohl S, Schönherr DM, Luigjes J, Denys D, Mueller UJ, Lenartz D, et al. Deep brain stimulation for treatmentrefractory obsessive compulsive disorder: a systematic review. BMC Psychiatry 2014;14:214.

66. Xie Y, Heida T, Stegenga J, Zhao Y, Moser A, Tronnier $\mathrm{V}$, et al. High-frequency electrical stimulation suppresses cholinergic accumbens interneurons in acute rat brain slices through GABA(B) receptors. Eur J Neurosci 2014;40:36533662.

67. Stidd DA, Vogelsang K, Krahl SE, Langevin JP, Fellous JM. Amygdala deep brain stimulation is superior to paroxetine treatment in a rat model of posttraumatic stress disorder. Brain Stimul 2013;6:837-844.

68. Koek RJ, Langevin JP, Krahl SE, Kosoyan HJ, Schwartz $\mathrm{HN}$, Chen JW, et al. Deep brain stimulation of the basolateral amygdala for treatment-refractory combat post-traumatic stress disorder (PTSD): study protocol for a pilot randomized controlled trial with blinded, staggered onset of stimulation. Trials 2014;15:356.

69. Morey RA, Gold AL, LaBar KS, Beall SK, Brown VM, Haswell CC, et al; Mid-Atlantic MIRECC Workgroup. Amygdala volume changes in posttraumatic stress disorder in a large case-controlled veterans group. Arch Gen Psychiatry 2012;69:1169-1178.

70. Herringa R, Phillips M, Almeida J, Insana S, Germain A. Post-traumatic stress symptoms correlate with smaller subgenual cingulate, caudate, and insula volumes in unmedicated combat veterans. Psychiatry Res 2012;203:139-145.

71. Langevin JP, De Salles AA, Kosoyan HP, Krahl SE. Deep brain stimulation of the amygdala alleviates post-traumatic stress disorder symptoms in a rat model. J Psychiatr Res 2010;44:1241-1245.

72. Peña DF, Engineer ND, McIntyre CK. Rapid remission of conditioned fear expression with extinction training paired with vagus nerve stimulation. Biol Psychiatry 2013;73:10711077. 